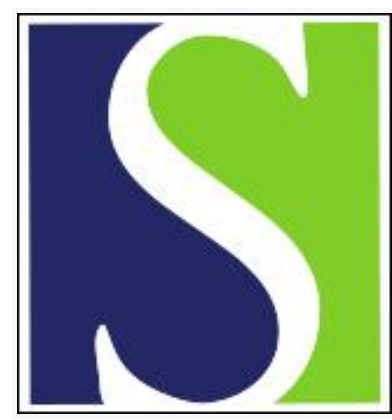

Scand J Work Environ Health 2004;30(1):36-46

https://doi.org/10.5271/sjweh.763

Issue date: Feb 2004

Costs, benefits and effectiveness of worksite physical activity counseling from the employer's perspective

by Proper KI, de Bruyne MC, Hildebrandt VH, van der Beek AJ, Meerding WJ, van Mechelen W

Affiliation: TNO Work and Employment, PO Box 718, NL-2130 AS Hoofddorp, The Netherlands. K.Proper@arbeid.tno.nl

Refers to the following texts of the Journal: $2002 ; 28(2): 75-84$

2002;28(2):85-93

The following articles refer to this text: $2007 ; 33(3): 161-164$;

2010;36(4):273-288; 2012;38(5):393-408; 2020;46(2):127-142

Key terms: absenteeism; efficiency; employer counseling; financial impact; intervention; physical activity; physical activity counseling; physical fitness; randomized controlled trial; workplace; worksite

This article in PubMed: www.ncbi.nlm.nih.gov/pubmed/15018027

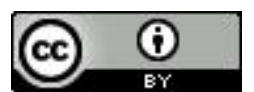




\title{
Costs, benefits and effectiveness of worksite physical activity counseling from the employer's perspective
}

\author{
by Karin I Proper, PhD, ${ }^{1,2,3}$ Martine C de Bruyne, PhD, ${ }^{4}$ Vincent H Hildebrandt, MD, ${ }^{1,3}$ Allard J van der \\ Beek, PhD, ${ }^{2,3}$ Willem Jan Meerding, MSc, ${ }^{5}$ Willem van Mechelen, $M D^{2,3}$
}

\begin{abstract}
Proper Kl, de Bruyne MC, Hildebrandt VH, van der Beek AJ, Meerding WJ, van Mechelen W. Costs, benefits and effectiveness of worksite physical activity counseling from the employer's perspective. Scand J Work Environ Health 2004;30(1):36-46.
\end{abstract}

\begin{abstract}
Objectives This study evaluated the impact of worksite physical activity counseling using cost-benefit and cost-effectiveness analyses.

Methods Civil servants $(\mathrm{N}=299)$ were randomly assigned to an intervention $(\mathrm{N}=131)$ or control $(\mathrm{N}=168)$ group for 9 months. The intervention costs were compared with the monetary benefits gained from reduced sick leave. In addition, the intervention costs minus the monetary benefits from sick leave reduction were compared with the effects (percentage meeting the public health recommendation for moderate-intensity physical activity, energy expenditure, cardiorespiratory fitness, and upper extremity symptoms).

Results The intervention costs were EUR 430 per participant, and the benefits were EUR 125 due to sick leave during the intervention period, for net total costs of EUR 305 for the intervention. During the same 9-month period the year after the intervention, the benefits from sick leave reduction were EUR 635. No statistically significant differences in costs and benefits were found between the groups. As to the cost-effectiveness, improvement in energy expenditure and cardiorespiratory fitness was observed at higher costs. The point estimates of the cost-effectiveness ratios were EUR 5.2 (without imputation of effect data) and EUR 2.7 (with imputation of effect data) per extra kilocalorie of energy expenditure per day and EUR 235 (without imputation of effect data) and EUR 45.9 (with imputation of effect data) per beat per minute of decrease in submaximal heart rate.

Conclusions This study does not provide a financial reason for implementing worksite counseling intervention on physical activity on the short-term. However, positive effects were shown for energy expenditure and cardiorespiratory fitness.
\end{abstract}

Key terms absenteeism from work, efficiency, financial impact, intervention, physical fitness, randomized controlled trial, workplace.

Physical inactivity and its consequences are of major concern in Western society. Physical inactivity is associated with an increased risk of many chronic diseases, such as cardiovascular disease $(1,2)$ and some types of cancer (3-5). Another consequence of physical inactivity is overweight. During the last few decades, the prevalence of overweight and obesity has increased dramatically. Currently, in The Netherlands, the prevalence of obesity is approximately $10 \%$, whereas in the United Kingdom and the United States (US), this percentage is even twofold greater [6, 7; see also the "Behavioral Risk Factor Surveillance System of the National Center for Chronic Disease Prevention \& Health Promotion (available from URL: http://apps.nccd.cdc.gov/brfss/Trends/ trendchart.asp?qkey $=10020 \&$ state $=$ US) and "Gezondheidstoestand van de Nederlandse bevolking" of the

1 TNO Work and Employment, Hoofddorp, The Netherlands.

2 Department of Social Medicine and Institute for Research in Extramural Medicine, VU University Medical Center, Amsterdam, The Netherlands.

3 Body@Work, Research Center Physical Activity, Work and Health, TNO-VUmc, The Netherlands.

4 Health Technology Assessment Unit, Institute for Research in Extramural Medicine, VU University Medical Center, Amsterdam, The Netherlands.

5 Department of Public Health, Faculty of Medicine, Erasmus MC University Medical Center Rotterdam, The Netherlands.

Reprint requests to: Ms Karin Proper, TNO Work and Employment, PO Box 718, NL-2130 AS Hoofddorp, The Netherlands. [E-mail: K.Proper@arbeid.tno.nl] 
Centraal Bureau voor de Statistiek, Voorburg/Heerlen, 2002 (available from URL: http://statline.cbs.nl/ StatWeb/table.asp?PA=7068gi\&D1=92-135\&D2=(111) $-1 \& D M=S L N L \& L A=n 1 \& T T=2)]$. The consequences for both public health and economic impact are enormous. In Europe, obesity-related costs have been estimated at $1-5 \%$ of the total health care expenditure (810). Besides, overweight or obese employees appear to be absent more often from work, and, as a consequence, a loss of productivity occurs (11-13).

Despite the well-documented benefits, $60 \%$ of the US adult population and $55 \%$ of Dutch adults are not physically active enough according to the public health recommendation for moderate-intensity physical activity (14-16).

Employers in Western countries have invested increasingly in both worksite physical activity programs and comprehensive health promotion intervention (17). The potential benefits expected by employers vary considerably and are, among others, improved health, reduced sick leave, improved productivity, and improved company image. Although the effectiveness of health promotion intervention at worksites has been studied, limited evidence is available about the efficiency (ie, the financial impact of such programs for companies). Therefore, Harris et al (18) recommended more research on the financial impact of such intervention. Insight into the efficiency of health promotion intervention at a worksite can be used to support the decision-making of the employer. The aim of this paper was to evaluate the efficiency of physical activity counseling as a form of intervention at the worksite by means of a cost-benefit and a cost-effectiveness analysis.

\section{Participants and methods}

\section{Study design}

A randomized controlled trial was conducted. The participants were recruited from three municipal services of a Dutch town, Enschede. The criteria for inclusion were (i) being a civil servant, (ii) performing office work, (iii) working for at least 24 hours a week at the local municipal service of Enschede, (iv) having a contract until at least the time of the posttest. Furthermore, an informed consent form had to be signed before the baseline measurements. The study protocol was approved by the Medical Ethical Committee of VU University Medical Center.

\section{Randomization}

All the eligible employees who registered for the information session and who agreed to volunteer for the study were randomized. The randomization program was drawn up by a statistician who was not involved in the project. As a larger loss to follow-up was expected among the controls, a distribution of 45-55\% was chosen for the number of intervention and control participants, respectively. Randomization was done at the level of the work unit $(\mathrm{N}=70)$ and within each municipal service $(\mathrm{N}=3)$ because of the anticipated influence of the intervention on colleagues working at the same unit and the need for approximately equal numbers of intervention and control participants within each municipal service. After the participants were tested at baseline, the coordinator of the fitness and health tests, who did not perform the measurements, assigned each participant to either the intervention group $(\mathrm{N}=131)$ or the control group ( $\mathrm{N}=168)$. The persons who assisted with the tests were blinded with respect to the allocation of the participants to the groups.

\section{Intervention}

For 9 months (ie, from May 2000 until January 2001) the intervention participants were offered seven consultations, all of which took place during worktime for approximately 20 minutes each. The counseling was mainly aimed at the promotion of physical activity and healthy dietary habits using standardized protocols and the individual's stage of behavior change as guides (19, 20 ). The stage of behavior change was determined during the baseline measurements, and it was checked during the first consultation. During the first two consultations, the test results were discussed, and the counselor offered tailored information and advice on physical activity and healthy dietary habits while keeping in mind the individual's stage of behavior change. With the mutual agreement of the counselor and employee, a plan was devised to improve the physical activity and nutrition behavior based on the individual stage of behavior change. Progression according to the plan was further discussed during the remaining five consultations. The number of consultations $(\mathrm{N}=7)$ was chosen on the basis of the experience of the counselor in agreement with the municipal service. Both the intervention participants and the controls received general written information about the following life-style factors: physical activity, nutrition, alcohol, smoking, (work) stress, and musculoskeletal symptoms. The control group did not, however, receive the counseling intervention.

\section{Study population}

Figure 1 presents a flow chart indicating the progress of participants during the study period. Out of the 


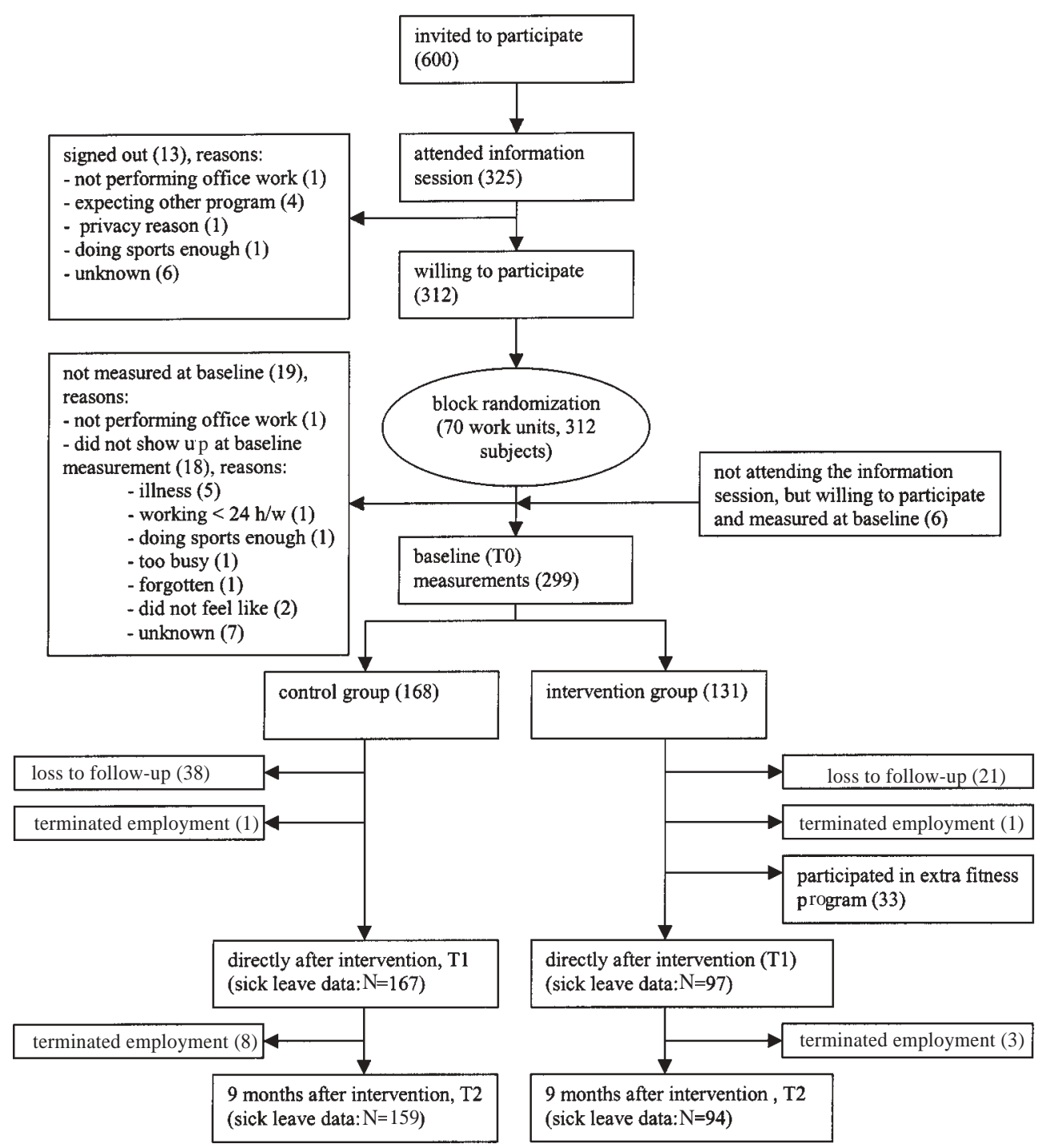

Figure 1. How chart showing the progress of the participants during the study period.

600 employees invited to attend the information session, 299 volunteers were measured at baseline and randomized into the intervention group $(\mathrm{N}=131)$ or the control group ( $\mathrm{N}=168)$. Sick leave data were missing only for those who terminated employment at the municipal service between the start of the intervention and January 2002. In the 9-month period during the intervention, one intervention participant and one control terminated employment. After the intervention (from February 2001 until January 2002), another 11 subjects stopped working at the municipal service ( 3 intervention participants and 8 controls). Within the control group, it appeared that those who did not complete one of the follow-up measurements (ie, questionnaire, interview or fitness test) differed from those who did complete these measurements in that the dropouts averaged more days of sick leave in the 9-month periods of data collection (before, during and after the intervention). This was not the case for the intervention group in that no dif- ferences in sick leave data were observed between the dropouts and those who continued in the study.

There were no notable differences in the demographic factors, physical activity, fitness, or health between the participants who withdrew from the study and those who continued. Table 1 presents the baseline characteristics of both study groups. Randomization appeared to be successful in that no significant differences were observed between the study groups at baseline. Moreover, it can be seen that the sick leave data were skewed; almost two-thirds of the participants had not been on sick leave during the 9 months preceding the start of the intervention (skewness of sick leave rate 3.7 and 4.6 for the intervention and control groups, respectively).

\section{Outcome measures}

For the economic evaluation of the study, the outcome measures were sick leave, physical activity, fitness, and 
Table 1. Baseline characteristics of the study population. ${ }^{a}$

\begin{tabular}{|c|c|c|c|c|c|c|c|c|c|c|c|c|}
\hline & \multicolumn{2}{|c|}{$\begin{array}{l}\text { Mean age } \\
\text { (years) }\end{array}$} & \multirow[t]{2}{*}{$\begin{array}{c}\text { Gender } \\
\text { (women) } \\
\text { (\%) }\end{array}$} & \multirow[t]{2}{*}{$\begin{array}{l}\text { Higher } \\
\text { educa- } \\
\text { tion } \\
(\%)\end{array}$} & \multirow[t]{2}{*}{$\begin{array}{c}\text { Active } \\
\text { enough } \\
(\%)\end{array}$} & \multicolumn{2}{|c|}{$\begin{array}{l}\text { Energy } \\
\text { expenditure } \\
\text { (kcal/day) }\end{array}$} & $\begin{array}{l}\text { Submaximal } \\
\text { heart rate } \\
\text { (days) }\end{array}$ & \multirow{2}{*}{$\begin{array}{c}\text { Upper } \\
\text { extremity } \\
\text { symptoms } \\
(\%)\end{array}$} & $\begin{array}{c}\text { Sick } \\
\text { leave rate } \\
\text { (days) }\end{array}$ & \multirow{2}{*}{$\begin{array}{c}\text { Sick leave } \\
\text { frequency } \\
\text { (times) } \\
\text { Mean SD }\end{array}$} & \multirow{2}{*}{$\begin{array}{c}\text { Sick } \\
\text { leave } \\
\text { preva- } \\
\text { lence } \\
(\%)\end{array}$} \\
\hline & Mean & SD & & & & Mean & SD & Mean SD & & Mean SD & & \\
\hline Intervention group ( $\mathrm{N}=97$ ) & 43.8 & 8.1 & 27.8 & 63.9 & 45.7 & 1197 & 451 & 13610.7 & 74.0 & 17.242 .1 & 1.31 .5 & 63.9 \\
\hline Control group $(\mathrm{N}=167)$ & 43.7 & 9.3 & 38.9 & 62.7 & 37.0 & 1159 & 631 & 13611.8 & 63.5 & 15.241 .0 & 1.31 .4 & 62.9 \\
\hline
\end{tabular}

a There were no significant differences between the groups.

${ }^{b}$ Performing at least 30 minutes of moderate intensity physical activities on at least 5 days a week.

musculoskeletal symptoms. Except for sick leave, these included the primary outcome measures of the study evaluating the effectiveness of the counseling intervention (21). In the effectiveness study, two more definitions of physical activity (sport index and leisure-time index) were applied, as well as an evaluation of lowback symptoms. For practical reasons, not all the definitions or outcome measures were applied in the economic evaluation. The secondary outcome measures of the study with respect to the effectiveness of the counseling were body composition, blood pressure, and total blood cholesterol.

The measurements took place 2 weeks before the first consultation (April 2000) and directly after the 9month intervention (January 2001). Sick leave (excluding absence due to holidays and pregnancy) was determined in the records of the personnel department of each municipal service. Data from the same 9-month period (May-January) in the year before (1999-2000), during (2000-2001), and after the intervention (2001-2002) were collected. For the purpose of the economic evaluation, physical activity was made operational in the following two ways: (i) by ensuring that the public health recommendation for moderate-intensity physical activity was met (16) and (ii) by assessing the total energy expenditure. The participants who reported participation in moderate-intensity physical activities for a cumulative minimum of 30 minutes a day, for 5 or more days a week, were considered active. The total energy expenditure was assessed using a structured interview, 7-day physical activity recall (PAR) (22-24), and it was expressed as kilocalories per day, which was adjusted for body weight. Fitness was expressed as cardiorespiratory fitness and was measured using a submaximal bicycle ergometer test $(25,26)$. To evaluate the change in cardiorespiratory fitness, the average heart rate during the last 2 minutes of cycling was used as the measure (ie, the submaximal heart rate). As to musculoskeletal symptoms, upper-extremity symptoms were chosen because of their high prevalence in the study population. The 3-month prevalence of upper-extremity symptoms was assessed using a validated Dutch version of the Nordic questionnaire $(27,28)$.

\section{Economic evaluation}

A cost-benefit analysis was carried out to compare the intervention costs with the monetary benefits due to sick leave reduction. For the remaining outcome measures (ie, recommendation for moderate-intensity physical activity, energy expenditure, cardiorespiratory fitness, and upper-extremity symptoms), a cost-effectiveness ratio was calculated.

The company perspective was used as the basis for the economic evaluation. In other words, only costs relevant to the company (ie, the municipal services) were considered, notably intervention costs and indirect costs (ie, costs due to productivity loss on the part of the participants). Direct health care costs were not included because they were not accountable for by the municipal service. The intervention costs included expenses that were directly related to the implementation of the individual counseling program. These costs were the amounts of money that the three municipal services would have had to pay for the intervention without interference of the study, and without the costs of the control group. These costs included the development and management of the program, the information session, the consultation with the sports physician who gave feedback about test results, the written information, and the individual counseling intervention given by the counselor. For the intervention group, the costs of the fitness and health tests (pre- and posttests) were also included, since these tests were part of the intervention offered. The intervention costs were calculated using the market price that had to be paid by the company. We also considered costs due to the estimated time spent by employees of the personnel department while arranging the time schedules for the information sessions, the fitness and health tests, and the individual counseling. Monetary benefits of the intervention included reduction of costs due to sick leave. Both the time spent by the personnel department employees and the benefits due to reduced sick leave were valued using the mean salary costs of the civil servants working in the municipal services concerned. Salary costs included the gross salary, the employer's social benefits, and the vacation allowance. The mean salary costs of the civil servants 
was EUR 41105.00 per year. To calculate these costs per day, the costs per year were divided by 12 , and subsequently divided by 30.7 , which is the average number of calendar days per month for the period May until January. Thus the mean salary cost per calendar day was EUR 112 when based on a production elasticity of 1.0 for the worktime.

\section{Cost-benefit analysis}

For the cost-benefit analysis, the costs of the monetary benefits due to reduced sick leave were calculated for the intervention period (from May 2000 until January 2001). Subsequently, the single expenditures of the intervention (ie, intervention costs and the costs due to the time spent by the personnel department) were compared with the monetary benefits of sick leave reduction during the intervention period. For the same 9-month period after the intervention (from May 2001 until January 2002), the difference in the monetary benefits due to sick leave reduction between the intervention group and the control group was calculated. Because of the gap of 3 months between the two 9-month periods (February 2001-April 2001), no comparison was made between the benefits in the year after the intervention and the intervention costs. Moreover, the intervention costs had already been taken into account in the former analysis.

\section{Cost-effectiveness analyses}

To calculate the cost-effectiveness ratios, we divided the incremental costs of the intervention group compared with those of the control group by the incremental effects for each of the effect measures separately. In this analysis, we used total costs by summing costs of the intervention and sick leave. Thus, in our cost-effectiveness analyses, all costs and monetary benefits were put in the numerator and compared with the effect in the nominator. For the cost-effectiveness analysis, only benefits due to a reduction in sick leave during the intervention period were considered, in order to evaluate the differences in costs and effects in the same period (ie, from May 2000 until January 2001).

\section{Statistical analysis}

Unadjusted differences between the two study groups are presented, as the confounders were shown to hardly influence the results (21). For the cost-benefit analysis, the differences in the mean intervention costs and in the mean benefits due to sick leave reduction were compared between the intervention group and the control group using bias-corrected and accelerated bootstrapping with 2000 as the number of replications (29). In doing so, $95 \%$ confidence intervals $(95 \% \mathrm{CI})$ were computed. Bootstrapping is a suitable method for analyzing cost data, as cost data are usually highly skewed and bootstrapping does not make any assumptions about the distribution of the data as is done with traditional statistical methods, such as the Student's t-test (29). For the cost-effectiveness analyses, the mean effects per study group were calculated using the delta score (posttest minus pretest). Subsequently, cost-effectiveness ratios were calculated by dividing the difference in the mean total costs (ie, including monetary benefits due to sick leave) between the two study groups by the difference in the mean effects. Confidence intervals for the costeffectiveness ratios were calculated again with bootstrapping, using the bias-corrected percentile method with 5000 replications. For each outcome measure used in this evaluation, cost-effectiveness ratios were plotted on a cost-effectiveness plane (30). The cost-effectiveness plane consists of four quadrants with a horizontal axis indicating the effectiveness of the intervention and the vertical axis indicating the costs.

\section{Sensitivity analysis}

Three sensitivity analyses were conducted. First, for The Netherlands, an elasticity measure between labor time and labor production was estimated to be 0.8 , which means that a reduction of $100 \%$ in labor time results in a decrease of $80 \%$ in production (31). In this paper, the results were based on an elasticity of 0.8 . The sensitivity analysis was conducted to compare the results with an elasticity of 0.5 and 1.0. Second, because of loss to follow-up, there were missing values in the effect measures, but not in the cost measures. As a consequence, for the analyses, we could not use cost data of participants with missing effect measures, as a result of which the power of the economic evaluation decreased. Moreover, the mean total costs taken into account differed per effect measure due to differences in the participant values that are missing for each effect measure. Therefore, to enhance the power and to have equal costs per effect measure, a sensitivity analysis was performed imputing data as to the effect measures. Imputation was done by the "last value carried forward" method, implying the baseline value. Third, a sensitivity analysis was performed to investigate the impact on the results when the costs of participants associated with the loss of worktime were included and, thereby, loss of productivity due to the time spent in the information session, the fitness and health tests, and the visits to the counselor. In the main analyses, these costs were not taken into account, since almost all the intervention participants reported that they had compensated for this in their own time, and thereby these costs were not accountable for by the municipal service. 


\section{Results}

\section{Cost-benefit analysis}

The intervention costs were EUR 430 per participant (table 2). Table 3 shows the mean intervention costs and sick leave costs per employee during the intervention period. No statistically significant differences were found for the total costs or the sick leave costs between the two study groups. During the intervention period, the intervention group had lower costs due to sick leave (mean difference EUR -125, 95\% CI EUR -13861062). The mean total costs during the intervention were higher in the intervention group than in the control group (mean difference EUR 305, 95\% CI EUR -10291419). In the year after the intervention, the benefits due to a reduction in sick leave increased further, the mean difference in sick leave costs between the two groups being EUR -635 (95\% CI EUR -1885-814) in favor of the intervention.

\section{Efects of the intervention}

In table 4, the mean effects of the counseling on the outcome measures are presented. For a more-detailed presentation of the effects, we refer readers to another paper (21). A significant positive intervention effect was observed for energy expenditure. The intervention participants expended more kilocalories per day, whereas the controls decreased their energy expenditure. For cardiorespiratory fitness, the same positive phenomenon was observed. The intervention subjects improved their fitness level (ie, decreased their submaximal heart rate) in contrast with the controls, whose performance in the submaximal bicycle ergometer test deteriorated. There was no significant effect on the proportion of subjects meeting the public health recommendation for moderate-intensity physical activity. A decrease in the proportion of subjects meeting this recommendation decreased in both the intervention group $(6.6 \%)$ and the control group $(6.0 \%)$. Furthermore, although the prevalence of upper-extremity symptoms decreased more in the intervention group than in the control group (17.9\% versus $6.2 \%)$, no statistically significant effect was found.

\section{Cost-effectiveness analyses}

Figures 2 to 5 show the cost-effectiveness planes for each outcome measure. Except for the number of participants meeting the public health recommendation for physical activity, most of the incremental cost-effect pairs of the other outcomes were in the northeast quadrant $(90 \%, 96 \%$, and $77 \%$ for energy expenditure, submaximal heart rate, and upper extremity symptoms, respectively), indicating positive effects at higher costs for the counseling intervention when compared with the control condition. In particular, for energy expenditure and cardiorespiratory fitness, the planes clearly indicate

Table 2. Costs of intervention for the 98 intervention participants.

\begin{tabular}{lc}
\hline Type of intervention cost & Cost (euros) \\
\hline Implementation a & 41907 \\
Time spent by Personnel Department & 223 \\
Intervention for 98 employees & 42130 \\
Intervention per employee & 430 \\
\hline
\end{tabular}

a Based on the market price to be paid by the municipal service.

Table 3. Mean costs ${ }^{a}$ for the intervention and control groups (in euros) during and after the intervention period.

\begin{tabular}{|c|c|c|c|c|c|c|}
\hline & \multirow{2}{*}{$\begin{array}{l}\text { Average total } \\
\text { days of sick leave } \\
\text { (mean) }\end{array}$} & \multirow{2}{*}{$\begin{array}{l}\text { Intervention } \\
\text { costs } \\
\text { (mean) }\end{array}$} & \multicolumn{2}{|c|}{ Sick leave costs ${ }^{\mathrm{a}}$} & \multicolumn{2}{|c|}{ Total costs } \\
\hline & & & Mean & SD & Mean & SD \\
\hline \multicolumn{7}{|c|}{ Before the intervention (May 1999 - January 2000) } \\
\hline Intervention group $(\mathrm{N}=97)$ & 17.2 & . & . & . & . & . \\
\hline Control group ( $\mathrm{N}=167)$ & 15.2 & · & $\cdot$ & . & $\cdot$ & $\cdot$ \\
\hline \multicolumn{7}{|c|}{ During the intervention (May 2000 - January 2001) } \\
\hline Intervention group (N=97) & 21.5 & 430 & 1915 & 4814 & 2345 & \\
\hline Control group $(\mathrm{N}=167)$ & 22.9 & $0.0^{c}$ & 2040 & 5031 & 2040 & 5031 \\
\hline Difference between the groups ${ }^{b}$ & 1.4 & $430^{c}$ & $-125^{d}$ & $\cdot$ & $305^{e}$ & $\cdot$ \\
\hline \multicolumn{7}{|c|}{ After the intervention (May 2001 - January 2002) } \\
\hline Intervention group $(\mathrm{N}=94)$ & 20.5 & - & 1830 & 4666 & . & . \\
\hline Control group $(\mathrm{N}=159)$ & 27.6 & - & 2465 & 5568 & . & . \\
\hline Difference between the groups ${ }^{b}$ & 7.1 & - & $-635^{f}$ & $\cdot$ & · & $\cdot$ \\
\hline
\end{tabular}

a Costs calculated on the basis of the mean costs of the civil servant's salary on the basis of production elasticity of 0.8 for worktime (35).

b Negative difference indicates a positive balance (fewer costs in the intervention group than in the control group).

c No standard deviation or $95 \%$ confidence intervals could be calculated, since these costs were the same for all the intervention participants.

d $95 \%$ confidence interval: -1386-1062, obtained by bias correction and accelerated bootstrapping.

e 95\% confidence interval: 1029-1419, obtained by bias correction and accelerated bootstrapping.

$95 \%$ confidence interval: -1883 - 814 obtained by bias correction and accelerated bootstrapping. 
Table 4. Mean costs, effects, and cost-effectiveness ratios for the public health recommendation for physical activity , energy expenditure,

\begin{tabular}{|c|c|c|c|c|c|c|c|c|c|c|c|c|}
\hline & \multicolumn{6}{|c|}{ Public health recommendation met (\%) } & \multicolumn{6}{|c|}{ Energy expenditure (kcal/day) } \\
\hline & \multicolumn{2}{|c|}{ Costs } & \multicolumn{2}{|c|}{ Effects } & \multirow[t]{2}{*}{ Ratio $^{a}$} & \multirow[t]{2}{*}{$95 \% \mathrm{Cl}$} & \multicolumn{2}{|c|}{ Costs } & \multicolumn{2}{|c|}{ Effects } & \multirow[t]{2}{*}{ Ratio $^{a}$} & \multirow[t]{2}{*}{$95 \% \mathrm{Cl}$} \\
\hline & Mean & SD & Mean & SD & & & Mean & SD & Mean & SD & & \\
\hline \multicolumn{13}{|c|}{ Without imputation of effect data } \\
\hline Intervention group & 2508 & 5298 & -6.6 & 0.6 & . & & 2583 & 545 & 64.2 & 491 & . & \\
\hline Control group & 1947 & 5200 & -6.0 & 0.5 & -1030 & $-36535--591$ & 1578 & 4442 & -129 & 630 & 5.2 & $-4.9-27.4$ \\
\hline \multicolumn{13}{|c|}{ With imputation of effect data } \\
\hline Intervention group & 2381 & 4884 & -5.3 & 0.5 & & & 2416 & 4932 & 48.2 & 425 & . & \\
\hline Control group & 2137 & 5216 & -4.5 & 0.5 & -316 & $-52774--77.1$ & 2050 & 5044 & -86.4 & 518 & 2.7 & $-9.1-27.8$ \\
\hline
\end{tabular}

${ }^{a} A$ positive cost-effectiveness ratio indicates the amount of money to be paid to achieve a positive intervention effect.

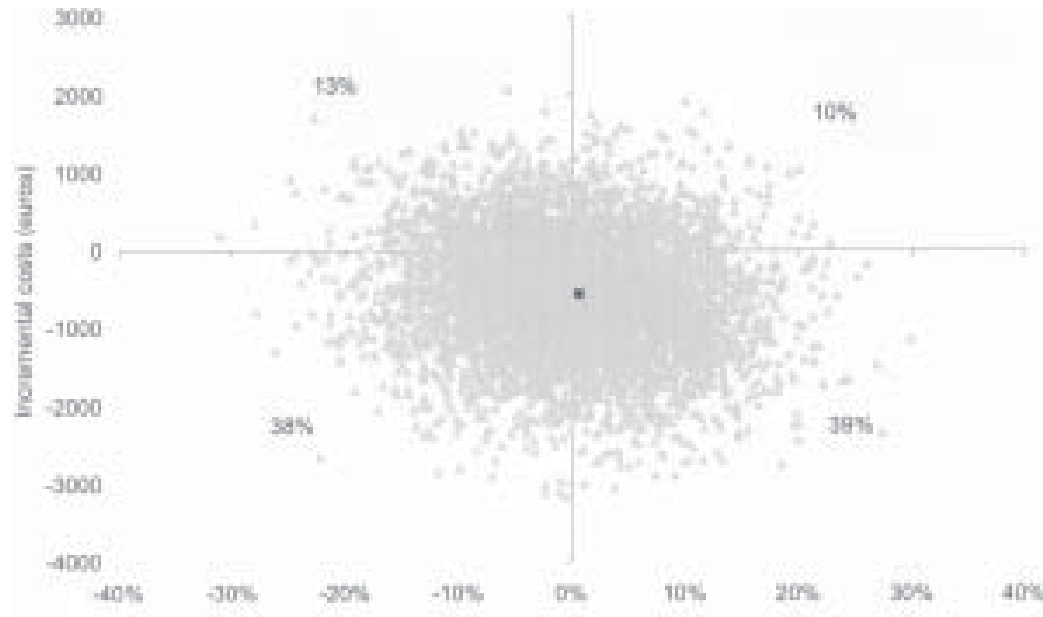

Dillarance in 5 persons mecting the publc heoth recammendation

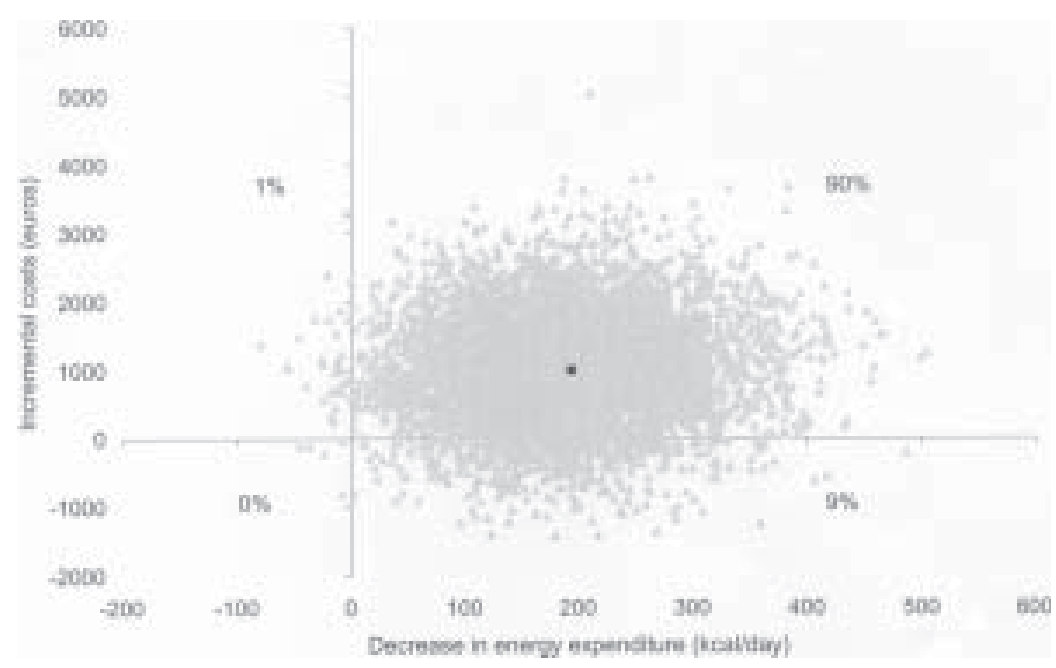

Figure 2. Cost-effectiveness plane for the public health recommendation on physical activity (point estimate-1030, $95 \% \mathrm{Cl}-36535-591)$. that the counseling was more effective than the control condition, as no or hardly any points appear in the west quadrants (1\% and $0 \%$, respectively). The point estimate of the cost-effectiveness ratio for energy expenditure is EUR 5.2 (95\%CI EUR -4.9-27.4) per extra kilocalorie per day per employee (table 4). For cardiorespiratory fitness, the ratio is EUR 235 (95\%CI EUR -10.0830) per beat per minute decrease in submaximal heart rate (table 4). For the public health recommendation for physical activity, most of the incremental cost-effect pairs were distributed in the southeast (39\%) and the southwest (38\%) quadrants. Moreover, the points considerably cross the origin of the plane, indicating that the counseling intervention was neither more costly nor more effective for the public health recommendation for physical activity. 
submaximal heart rate, and upper-extremity symptoms. The results are based on an elasticity measure of 0.8 . (See reference 23.)

\begin{tabular}{|c|c|c|c|c|c|c|c|c|c|c|c|}
\hline \multicolumn{6}{|c|}{ Submaximal heart rate (beats/min) } & \multicolumn{6}{|c|}{ Upper-extremity symptoms (\%) } \\
\hline \multicolumn{2}{|c|}{ Costs } & \multicolumn{2}{|c|}{ Effects } & \multirow[t]{2}{*}{ Ratio $^{a}$} & \multirow[t]{2}{*}{$95 \% \mathrm{Cl}$} & \multicolumn{2}{|c|}{ Costs } & \multicolumn{2}{|c|}{ Effects } & \multirow[t]{2}{*}{ Ratio $^{a}$} & \multirow[t]{2}{*}{$95 \% \mathrm{Cl}$} \\
\hline Mean & SD & Mean & SD & & & Mean & SD & Mean & SD & & \\
\hline 2223 & 4786 & -2.2 & 8.9 & . & . & 2461 & 5237 & -17.9 & 0.5 & . & . \\
\hline 1118 & 3352 & 2.5 & 8.5 & 235 & $-10.0-827$ & 1829 & 4939 & -6.2 & 0.5 & 53.6 & $-101-809$ \\
\hline 2113 & 4292 & -1.7 & 7.7 & . & & 2365 & 4835 & -14.6 & 0.5 & . & . \\
\hline 1963 & 4806 & 1.6 & 6.9 & 45.9 & $-314-573$ & 2040 & 5031 & -4.8 & 0.5 & 33.2 & $-167-609$ \\
\hline
\end{tabular}
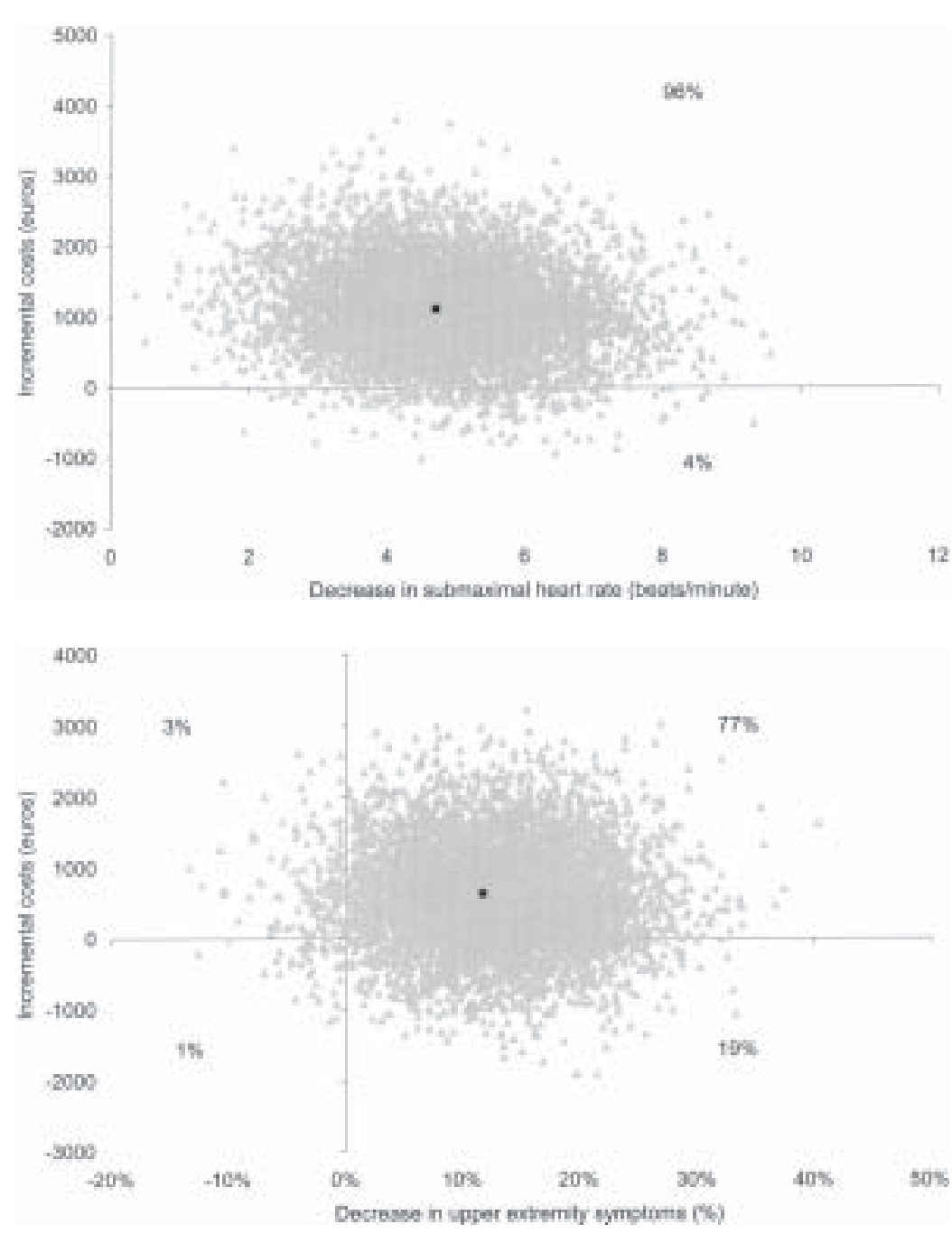

Figure 4. Cost-effectiveness plane for submaximal heart rate (point estimate 235, $95 \% \mathrm{Cl}-10.0-827)$.

\section{Sensitivity analysis}

Use of an elasticity measure of 0.5 resulted in lower cost-effectiveness ratios when compared with 0.8 (ratios $-940,4.0,181$, and 47.2 for meeting the public health recommendation, energy expenditure, submaximal heart rate, and upper extremity symptoms, respectively). Analogously, using an elasticity measure of 1.0 resulted in higher cost-effectiveness ratios (ratios: $-1090,5.9,271,57.9$, respectively). It would be expected that the lower the elasticity, the higher the cost-effectiveness ratios, and thereby the less favorable the results, due to more costs because of less savings from sick leave reduction. However, the "unexpected" trend observed was caused by the missing values in the control group, including participants with a long sick leave 
duration. As a consequence, particularly for energy expenditure and submaximal heart rate, the costs of the control group decreased substantially, namely, from EUR 2040 to EUR 1558 and EUR 1118, respectively (tables 3 and 4), and were thereby markedly lower than the sick leave costs of the intervention group. Only for submaximal heart rate did the cost-effectiveness ratio change from statistical nonsignificance with a production elasticity of 0.8 for labor time to a statistically significant cost-effectiveness ratio using an elasticity measure of 0.5 (EUR 181, 95\% CI EUR 25.0-586) in favor of the counseling, because, with a lower elasticity, the confidence interval becomes narrower. For the other analyses, the use of an elasticity measure of 0.5 or 1.0 had no impact on the statistical significance of the outcome of the economic evaluation.

The results of the imputation of the effect data are also presented in table 4 . The effect measures within each study group were slightly smaller, and conclusions as to the effectiveness of the counseling remained the same when comparisons were made with or without the imputation data. The costs in the study groups were approximately the same for each outcome measure (table 4). However, as there were still some missing data per outcome (eg, caused by the fact that some participants were not able to perform the submaximal bicycle ergometer test), the costs varied slightly per outcome measure. Furthermore, as (almost) all costs were taken into account (ie, including the persons who had been sick for a long time), the mean total costs of the control group increased. As a consequence, the difference in costs between the two groups decreased and thus resulted in lower cost-effectiveness ratios than without the imputation. For example, the ratios after the imputation of the effect data for energy expenditure and submaximal heart rate were 2.7 and 45.9, respectively, versus 5.2 and 235 , respectively (table 4 ). The confidence intervals of the cost-effectiveness ratios were still very large and not statistically significant. Contrary to the analyses without data imputation, the use of an elasticity measure of 0.5 resulted in a larger difference in costs between the groups than an elasticity measure of $0.8 \mathrm{did}$, leading to higher cost-effectiveness ratios. Use of an elasticity measure of 1.0 led to lower ratios.

Including the costs due to the time spent by the employees on attendance in the information session, tests, and counseling (EUR 73.0 16.6 ) did not influence the outcome of the cost-effectiveness.

\section{Discussion}

As to the cost-benefit analysis, no evidence was found for significant cost savings. Because there was an increasing trend for sick leave (costs) in the control group, the counseling intervention might reveal significant positive net benefits in the longer term. Although not statistically significant, the difference in sick leave costs between the intervention group and the control group was large and might be considered relevant from the employer's perspective. As is common in economic evaluations, the trial was underpowered to find statistically significant differences in costs between the groups since the cost data were skewed. Relatively few participants were responsible for a relatively large proportion of the costs, a situation which led to wide confidence intervals of the differences, and, in cases of small numbers, to tentative conclusions. Even though we dealt with the skewed data with bootstrapping, the power of the study was not improved.

With respect to the cost-effectiveness, our findings showed that an improvement in energy expenditure and cardiorespiratory fitness could be gained in the intervention group at higher costs. Based on an elasticity measure of 0.8, the cost-effectiveness ratios were EUR 5.2 and EUR 235 per extra kilocalorie energy expenditure per day and per decrease in beat per minute of the submaximal heart rate per employee, respectively. However, due to the very wide (statistically nonsignificant) confidence intervals, we cannot say with certainty that this is the amount of money to be invested in order to achieve improved energy expenditure and fitness levels. Moreover, there were some other uncertainties, which we tried to overcome in the sensitivity analyses. Because of a selective group of missing values as to the outcome measures, namely, values for those who had been sick for a long time, the results should be interpreted with caution. Without the costs of the persons who were missing in the outcome measures being taken into account, the mean costs in the control group decreased substantially and were thereby much lower than the costs of the intervention group. Thus the use of an elasticity measure of 0.5 led to a larger decrease in costs in the intervention group than in the control group and produced a smaller difference in costs between the two groups than the elasticity measure of $0.8 \mathrm{did}$. This circumstance resulted in a lower cost-effectiveness ratio than for an elasticity of 0.8 .

Despite the counterarguments for imputing data (eg, imputed data are not real and may thereby misrepresent the effect), we decided to impute the data of the effect measures for the purpose of the economic evaluation. Notably, missing values of effect measures will lead to missing values of the cost data because the cost data of persons without effect measures cannot be used in the cost-effectiveness analyses. Moreover, generally, the power of an economic evaluation is low. Missing data will even decrease the statistical power to a greater extent. Therefore, by imputing data as to the effect 
measures under the condition that the effect measure will not (substantially) change, the power of the cost differences are increased. We imputed data by the "last value carried forward" method, which appeared to be conservative since the effect measures hardly changed, or even became somewhat smaller. From table 4, it can be seen that the ratios were more favorable for the counseling intervention, even though large confidence intervals were still observed. Hence the conclusion must be that effects on energy expenditure and cardiorespiratory fitness can be gained, but at a certain price.

A few comments should be made with respect to the analyses. First, the cost-benefit analysis presented in this study was actually a partial cost-benefit analysis. In a full cost-benefit analysis, all costs and all healthrelated effects are expressed in monetary units. In our analysis, we refrained from valuing the health effects because of the difficulties associated with the valuing. Therefore, we decided to conduct a cost-effectiveness analysis in addition to a cost-benefit analysis. In doing so, we compared all the costs and benefits of the intervention to the health-related effects. As sick leave can be valued and because it can be considered to fall into the "benefits" category with respect to the intervention, it was subtracted from the costs.

Second, several other potential benefits for the company were not included in our study, such as reduced employee turnover, productivity, commitment to the company, and improved corporate image. Most of these benefits are hard to measure and value; therefore we did not include these potential benefits. Although an economic evaluation is a useful tool for companies as they decide whether or not they benefit from the implementation of a physical activity program at their worksites, other benefits that are hard to determine should be weighed in the decision as well.

The health care costs, such as costs due to medical consumption or therapy, were not taken into account, since these costs were accountable for by the municipal service. On the basis of the fact that the study population was a "healthy" working population that did not frequently make use of health care, we assumed these costs have been low. Moreover, retrospective self-reports of the medical consumption and therapies indicated no substantial differences between the two groups.

Our results cannot easily be compared to the results of other studies evaluating the cost-benefits and costeffectiveness of similar interventions because of a lack of similar studies. Most studies have evaluated the economic impact of comprehensive health promotion programs instead of programs primarily aimed at improving physical activity. Moreover, the majority of the reviews on the economic outcomes of worksite health promotion are based on studies from the United States. In that country, the employer is responsible for the medical costs, which is not the case in The Netherlands. Hence an employer in the United States will benefit from reduced health care costs, while a Dutch employer will not.

Most of the reviews published suggest that worksite health promotion programs have a positive economic impact, a reduction in sick leave being an important component (32-34). However, considering the few randomized controlled studies that have been published with respect to the effectiveness of worksite physical activity programs on sick leave, no hard conclusion for a positive effect on sick leave can be drawn (35). For example, a recently published randomized controlled trial did not find that a worksite exercise program had a positive effect on sick leave (36), in contrast to the trial of Kerr \& Vos (37), who did observe a statistically significant effect on sick leave. As to the cost-effectiveness studies, Shephard (38) estimated the immediate return to be as much as USD 2 to USD 5 per US dollar invested. He suggested in his review of worksite fitness programs that, despite the limitations of many studies, exercise (particularly in the context of general health promotion) is both cost-effective and results in net benefits. Bowne et al (39) conducted a cost-benefit analysis of a fitness program at an insurance company. The adjusted estimates for the benefits and costs of the program for 1 year were USD 1106 and USD 451, respectively. In addition, Golaszewksi et al (40) conducted a cost-benefit analysis of a health and fitness program at a workplace with projections for an additional 10 years. The adjusted estimates for the benefits and costs were USD 139 million and USD 43 million, respectively, the benefit-to-cost ratio being USD 3.4 for the program.

In conclusion, this study did not find statistically significant differences in costs and benefits between the two study groups. However, in view of the positive effects found for energy expenditure and cardiorespiratory fitness, implementation of a worksite counseling program on physical activity may lead to long-term occupational or public health benefits.

\section{References}

1. Wannamethee SG, Shaper AG. Physical activity in the prevention of cardiovascular disease: an epidemiological perspective. Sports Med 2001;31:101-14.

2. Manson JE, Greenland P, Lacroix AZ, Stefanick ML, Mouton $\mathrm{CP}$, Oberman A, et al. Walking compared with vigorous exercise for the prevention of cardiovascular events in women. N Engl J Med 2002;347:716-25.

3. Levi F, Pasche C, Lucchini F, LaVecchia C. Occupational and leisure time physical activity and the risk of breast cancer. Eur J Cancer 1999;35:775-8.

4. Wannamethee SG, Shaper AG, Walker M. Physical activity and risk of cancer in middle-aged men. Br J Cancer 
2001;85:1311-6.

5. Boutron-Ruault MC, Senesse P, Meance S, Belghiti C, Faivre J. Energy intake, body mass index, physical activity, and the colorectal adenoma-carcinoma sequence. Nutr Cancer 2001;39:50-7.

6. Visscher TLS, Kromhout D, Seidell JC. Long-term and recent time trends in the prevalence of obesity among Dutch men and women. Int J Obes 2002;26:1218-24.

7. National Audit Office. Tackling obesity in England: report by the comptroller and auditor general. London: Her Majesty's Stationery Office; 2001.

8. Colditz GA. Economic costs of obesity and inactivity. Med Sci Sports Exerc 1999; 31 Suppl 11:663-7.

9. Seidell JC. The impact of obesity on health status: some implications for health care costs. Int J Obes Relat Metab Disord 1995;19 suppl 6:13-6.

10. Seidell J. Societal and personal costs of obesity. Exp Clin Endocrinol Diabetes 1998;106:7-9.

11. Tucker LA, Friedman GM. Obesity and absenteeism: an epidemiologic study of 10,825 employed adults. Am J Health Promot 1998;12:202-7.

12. Narbro K, Jonsson E, Larsson B, Waaler H, Wedel H, Sjostrom L. Economic consequences of sick-leave and early retirement in obese Swedish women. Int J Obes Relat Metab Disord 1996;20:895-903.

13. Visscher T. Meer arbeidsongeschiktheid: consequenties van overgewicht voor de volksgezondheid [More disability consequences of overweight for public health]. Voeding $\mathrm{Nu}$ 2000;4:29-31.

14. US Department of Health and Human Services. Physical activity and health: a report of the Surgeon General. Atlanta (GA): US Department of Health and Human Services, Centers for Disease Control and Prevention, National Center for Chronic Disease Prevention and Health Promotion; 1996.

15. Ooijendijk WTM, Hildebrandt VH, Stiggelbout M. Bewegen in Nederland 2000: eerste resultaten van de monitorstudie Bewegen en Gezondheid [Physical activity in the Netherlands 2000: first results of the monitoring study physical activity and health]. In: Ooijendijk WTM, Hildebrandt VH, Stiggelbout M, editors. Trendrapport Bewegen en Gezondheid 2000/2001 [Report of the trends as to physical activity and health 2000/2001]. Heerhugowaard: PlantijnCasparie; 2002. p 7-23.

16. Pate RR, Pratt M, Blair SN, Haskell WL, Macera CA, Bouchard C, et al. Physical activity and public health, a recommendation from the Centers for Disease Control and Prevention and the American College of Sports Medicine. JAMA 1995;273:402-7.

17. Dishman RK, Oldenburg B, O'Neal H, Shephard RJ. Worksite physical activity interventions. Am J Prev Med 1998; 15:344-61.

18. Harris JR, Holman PB, Carande-Kulis VG. Financial impact of health promotion: we need to know much more, but we know enough to act. Am J Health Promot 2001;15:378-82.

19. Prochaska JO, Marcus BJ. The transtheoretical model - the applications to exercise. In: Dishman RK, editor. Advances in exercise adherence. Champaign (IL): Human Kinetics; 1994. p 161-80.

20. Patrick K, Calfas KJ, Sallis JF, Long BJ. Basic principles of physical activity counseling: project PACE. In: Thomas RJ, editor. The heart and exercise: a practical guide for the clinician. New York (NY): Igaku-Shoin; 1996. p 33-50.

21. Proper KI, Hildebrandt VH, Van der Beek AJ, Twisk JWR, Van Mechelen W. Individual counseling and active lifestyle: a randomized controlled trial in a worksite setting. Am J Prev Med 2003;24:218-26.

22. Sallis JF, Haskell WL, Wood PD, Fortmann SP, Rogers T, Blair SN, et al. Physical activity assessment methodology in the Five-City project. Am J Epidemiol 1985;121:91-106.

23. Taylor CB, Coffey T, Berra K, Iaffaldano R, Cassey K, Haskell WL. Seven-day activity and self-report compared to a direct measure of physical activity. Am J Epidemiol 1984; 120:818-24.

24. Dishman RK, Steinhardt M. Reliability and concurrent validity for a seven-day recall of physical activity in college students. Med Sci Sports Exerc 1988;20:14-25.

25. Vos JA, Binkhorst RA. Fietsergometrie bij de begeleiding van training [Bicycle ergometry at the guidance of training]. Lochem: De Tijdstroom; 1987.

26. Åstrand P-O, Ryhming I. A nomogram for calculation of aerobic capacity (physical fitness) from pulse rate during submaximal work. J Appl Physiol 1954;7:218-21.

27. Kuorinka I, Jonsson B, Kilbom A, Vinterberg H, BieringSorensen F, Andersson G, et al. Standardised Nordic questionnaires for the analysis of musculoskeletal symptoms. Appl Ergon 1987;18:233-7.

28. Hildebrandt VH, Bongers PM, Van Dijk FJH, Kemper HC, Dul J. Dutch musculoskeletal questionnaire: description and basic qualities. Ergonomics 2001;44:1038-55.

29. Efron B, Tibshirani RJ. An introduction to the bootstrap. New York, London: Chapman \& Hall; 1993.

30. Van Hout BA, Gordon GS, Rutten FF. Cost, effects and c/e ratios alongside a clinical trial. Health Econ 1994;7:309-19.

31. De Koning J, Tuyl FAWM. The relation between labour time, production and employment. Rotterdam: Netherlands Economic Institute; 1984.

32. Pelletier KR. A review and analysis of the clinical- and costeffectiveness studies of comprehensive health promotion and disease management programs at the worksite: 1998-2000 update. Am J Health Promot 2001;16:107-16.

33. Aldana SG. Financial impact of health promotion programs: a comprehensive review of the literature. Am J Health Promot 2001;15:296-320.

34. Golaszewski T. Shining lights: studies that have most influenced the understanding of health promotion's financial impact. Am J Health Promot 2001;15:332-40.

35. Proper KI, Staal BJ, Hildebrandt VH, van der Beek AJ, van Mechelen W. Effectiveness of physical activity programs at worksites with respect to work-related outcomes [review]. Scand J Work Environ Health 2002;28(2):75-84.

36. Nurminen E, Malmivaara A, Ilmarinen J, Ylöstalo P, Mutanen P, Ahonen G, et al. Effectiveness of a worksite exercise program with respect to perceived work ability and sick leaves among women with physical work. Scand J Work Environ Health 2002;28(2):85-93.

37. Kerr JH, Vos MCH. Employee fitness programmes, absenteeism and general well-being. Work Stress 1993;7:179-90.

38. Shephard RJ. Current perspectives on the economics of fitness and sport with particular reference to worksite programmes. Sports Med 1989;7:286-309.

39. Bowne DW, Russel ML, Morgan JL, Optenberg SA, Clarke AE. Reduced disability and health care costs in an industrial fitness program. J Occup Med 1984;26:809-16.

40. Golaszewski T, Snow D, Lynch W, Yen L, Solomita D. A benefit-to-cost analysis of a worksite health promotion program. J Occup Med 1992;34:1164-72.

Received for publication: 14 April 2003 